IOS Press

\title{
Obituary
}

\section{Barry Cooper (1943-2015): The engine of Computability in Europe}

\author{
Benedikt Löwe \\ Institute for Logic, Language and Computation, Universiteit van Amsterdam, Postbus 94242, 1090 GE Amsterdam, The Netherlands \\ Fachbereich Mathematik, Universität Hamburg, Bundesstraße 55, 20146 Hamburg, Germany \\ Corpus Christi College, University of Cambridge, Cambridge CB2 1 RH, England \\ bloeweescience.uva.nl
}

\begin{abstract}
This note is not to be misunderstood as a general obituary touching all of the many facets of Barry's personality: the teacher, the researcher, the activist, and, in general, the enthusiastic supporter of good causes. Rather, it should be seen as the author's personal recollection of the crucial role that Barry played in the transition of Computability in Europe from European network proposal via conference and conference series to association.
\end{abstract}

Plans for a European network. One day in August 2003, a few months after I had moved to the ILLC in Amsterdam, Peter van Emde Boas came into my office and told me of an initiative to write a Marie Curie grant proposal for a network called "Computability in Europe" (CIE) as a successor of an earlier network called "Complexity, Logic, and Recursion Theory" (COLORET; 1994-1998). He asked me to contribute a few sentences about my work on infinite time Turing machines to the proposal text. I had no inkling that this conversation would become the starting point of something that is much larger than any European-funded network. I was added almost instantaneously to Barry Cooper's mailing list of people involved in the proposal, and received the first of many e-mails from Barry about CIE on 8 September 2003. Soon after that, Peter handed the coordination of the Amsterdam node in the network over to me.

The work on the CIE proposal was not my first interaction with Barry. I had first seen Barry when he was a keynote speaker at Logic Colloquium 1995 in Haifa, the very first major international conference I attended; Barry gave a plenary talk entitled Beyond Gödel's theorem - The failure to capture information content. Two years later, after Logic Colloquium 1997 in Leeds, I was co-authoring a survey paper with John Steel for the proceedings volume of the conference ${ }^{1}$ and Barry was the responsible editor for our paper. Barry arranged post-proceedings volumes by setting up a webpage that would list all papers that were promised for the volume, marked the responsible editor with a coloured ball, and listed the current status of the paper as being "in preparation", "with referee", "in revision", or "accepted". When I became an organiser of conferences and editor of post-proceedings volumes myself, for the conference series "Foundations of the Formal Sciences", ${ }^{2}$ I adopted Barry's system, unaware at the time that this was Barry's personal feature of editorial practice. Of course, later, when I co-edited books and special issues with Barry, ${ }^{3}$ I became one of the coloured balls myself.

The attentive reader may have noticed that the acronym used in the first paragraph was "CIE" rather than the current "CiE". This was something that was changed just a few days before the submission of the proposal. I personally remember it as one of the first instance of a rather prototypical disagreement between Barry and myself: Barry had a bold vision; I disagreed, often not with Barry's vision, but with Barry's proposed implementation of the vision; after some, from time to time rather heated, argument, we collaborated to implement Barry's vision; and finally, the outcome showed that Barry had been right from the very beginning.

\footnotetext{
${ }^{1}$ Benedikt Löwe, John R. Steel, An introduction to core model theory, in: Sets and Proofs, Invited Papers from the Logic Colloquium 97, S. Barry Cooper and John K. Truss, eds, London Mathematical Society Lecture Note Series, Vol. 258, University of Leeds, England, 6-13 July 1997, Cambridge, 1999, pp. 103-157.

${ }^{2}$ FotFS; with the first three conferences in Berlin (1999) and Bonn (2000 and 2001) and proceedings volumes published as a special issue in the journal Synthese and in the book series Trends in Logic.

${ }^{3}$ In total, I co-edited four books and six journal special issues with Barry.
} 


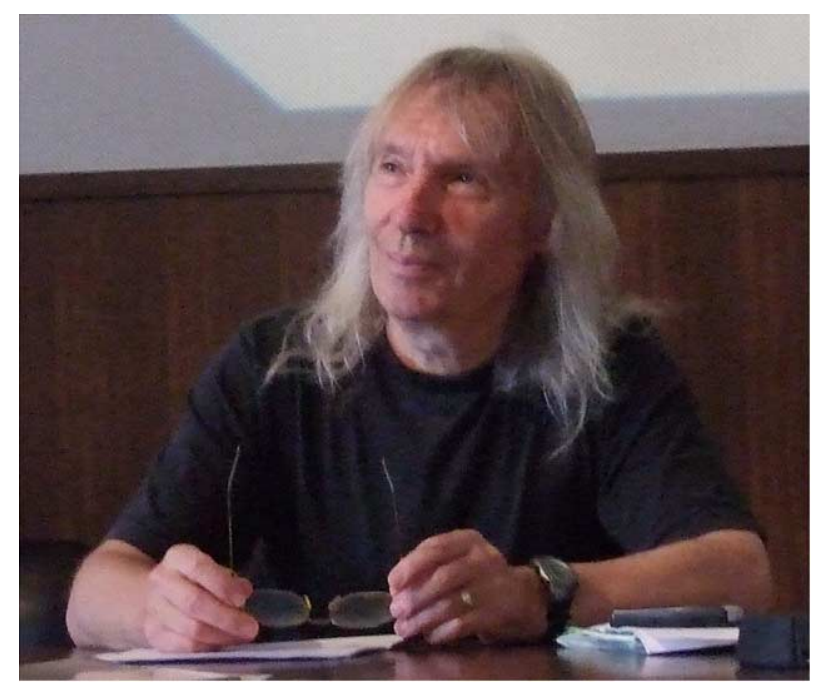

Figure 1. S. Barry Cooper during the opening of CiE 2007 in Siena. Photo taken by Peter van Emde Boas, June 2007.

However, my memory of the disagreement about the acronym CiE is flawed, as there was no heated argument at all: A few days before submission of the proposal, Barry asked all coordinators by e-mail: "A last minute question I got this from Klaus Keimel: 'Does it look more attractive to write CiE instead of CIE?' I tried it out - looks more

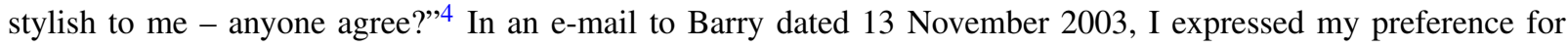
"CIE" and worried that people might get the acronym "CiE" wrong due to the slightly more complicated spelling. Barry did not respond to my message and went ahead with "CiE"; of course, by now we know that he was right not to worry.

The opening words of our 2003 proposal, written by Barry and reflecting his approach to the field, encapsulate very clearly many of the later features of CiE. I do not think that anyone but Barry was truly aware of the scope of this proposal at the time it was written:

It has been claimed that while the focus in 20th century mathematics was to develop grand formalisms like algebra and topology, the focus in the 21 st century will be on extracting data and algorithms. [...] We can see now that the world changed in 1936, in a way quite unrelated to the newspaper headlines of that year concerned with such things as the civil war in Spain, economic recession, and the Berlin Olympics. The end of that year saw the publication of a thirty-six page paper by a young mathematician, Alan Turing, claiming to solve a long-standing problem of the distinguished German mathematician David Hilbert. A byproduct of that solution was the first machine-based model of what it means for a number-theoretic function to be computable, and the description of what we now call a Universal Turing Machine. At a practical level, as Martin Davis describes in his 2001 book Engines of Logic: Mathematicians and the Origin of the Computer, the logic underlying such work became closely connected with the later development of real-life computers. The stored-program computer on one's desk is a descendant of that first universal machine. What is less often remembered is Turing's theoretical contribution to the understanding of the limitations on what computers can do. There are quite easily described arithmetical functions which are not computable by any computer, however powerful. And even the advent of quantum computers will not change this.

On 15 April 2004, we received news that the project was not funded; this rejection was the real start of the story of $\mathrm{CiE}$. Barry was strangely fond of stressing how $\mathrm{CiE}$ emerged from repeated failures: none of our four European

\footnotetext{
${ }^{4}$ E-mail from S.B.C. to the CiE coordinators, 12 November 2003. The original CiE coordinators were the people listed as node coordinators in the 2003 proposal: Klaus Ambos-Spies, Albert Atserias, S. Barry Cooper, Costas Dimitracopoulos, Sergey Goncharov, Benedikt Löwe, Dag Normann, Helmut Schwichtenberg, Andrea Sorbi, John V. Tucker, and Jiři Wiedermann.
} 
funding applications were successful. He told the story of how the powerful CiE community and its Association rose from the ashes after the defeats. He not only used this story in the presence of the Association members, but also recounted it to a much more general public in his opinion piece for the Northerner blog of the Guardian:

In 2003 I founded a geeky academic network called Computability in Europe (CiE), based on Alan Turing's scientific legacy, and attempted - unsuccessfully - to get EU funding. ${ }^{5}$

The Amsterdam conference and the creation of the conference series. The referees of our funding proposal had complained about the fact that the proposal was too much focused on traditional computability theory and that it did not pay proper attention to "new computational paradigms"; this particular phrase from the referee report became crucial for the development of our community. Shortly after the rejection notification, Barry rallied the troops with an e-mail that very characteristically contains a vision of many things that were to come:

There is some agreement that we need a CiE meeting to both help improve the focus of any new proposal, and as a basic step in raising the profile of computability as a research area.

One suggestion is we seek to synchronise such a meeting with some major related conference, e.g., LICS or an ASL European Logic Colloquium, although it might be hard to find one which would not negatively impact on the delicate balance in $\mathrm{CiE}$ between $\mathrm{CS}$ and logic (and on the outside perception of that balance). On the other hand, we could think of establishing a regular (annual/biennial) conference of our own - say ' $\mathrm{CiE} \mathrm{2005',} \mathrm{or}$ 'Computability 2005'. We could start modestly, with ambitions for growth. Offers to host such a meeting next year would be very welcome. ${ }^{6}$

After this e-mail, things developed very quickly. The same day, Barry and I exchanged several e-mails about having the proposed meeting in Amsterdam. Barry's proposed title was "Computability 2005: First Meeting of Computability in Europe (CiE)"; my counter-proposal, de-emphasizing the serial nature of the conference, was "Computability in Europe 2005: New Computational Paradigms". After talking to my colleagues Leen Torenvliet and Peter van Emde Boas in Amsterdam, the proposal to have CiE 2005 in Amsterdam was sent to the CiE coordinators on 26 April, and the dates of CiE 2005 were officially announced on 30 April.

In later years, it had become part of the narrative of the $\mathrm{CiE}$ conference series that we did not originally plan it as a series, but rather as a special coordination meeting for writing the revised proposal, and that it was the success of the first conference that forced the creation of a conference series upon us. However, Barry's April 2004 message cited above clearly shows that he had a series of conferences in mind even before the first was planned. His proposed title with the subtitle "first meeting of Computability in Europe" left no room for doubt about that. Among the coordinators, there were some who voiced concerns that the community does not need yet another conference series, and so my intention was to keep the decision about whether there would be a successor conference open. ${ }^{7}$ Of course, as we all know, this was yet another instance of the pattern of Barry's vision eventually prevailing against my initial resistance.

For Barry, it was clear that the success of the conference series depended on publications. Already in May 2004, he started making plans about a book planned in the style of a mathematical proceedings volume that would be connected to our Amsterdam conference. ${ }^{8}$ One of the obstacles that the new conference series needed to overcome was the huge difference in publication cultures between the involved disciplines: in mathematics, presenting at a conference does not constitute a publication; typically, everyone who wishes to present their results gets the chance; if a conference has a proceedings volume, the papers are submitted after the conference ("post-proceedings") and then refereed according to the standards of research journals; these proceedings volumes typically appear years, sometimes many years after the conference. In contrast, in computer science, a conference is, according to a famous

\footnotetext{
${ }^{5}$ S. Barry Cooper, The imitation game: How Benedict Cumberbatch brought Turing to life, The Northerner, The Guardian, 7 October 2014.

${ }^{6}$ E-mail from S.B.C. to the CiE community, 23 April 2004.

${ }^{7} \mathrm{E}-\mathrm{mail}$ by B.L. to the $\mathrm{CiE}$ coordinators, dated 3 May 2004: “[A]t CiE 2005, we should discuss our small-scale plans (will there be a $\mathrm{CiE}$ 2006 ? summer schools?)".

${ }^{8}$ S. Barry Cooper, Benedikt Löwe and Andrea Sorbi (eds), New Computational Paradigms: Changing Conceptions of What Is Computable, Springer, New York, 2008.
} 


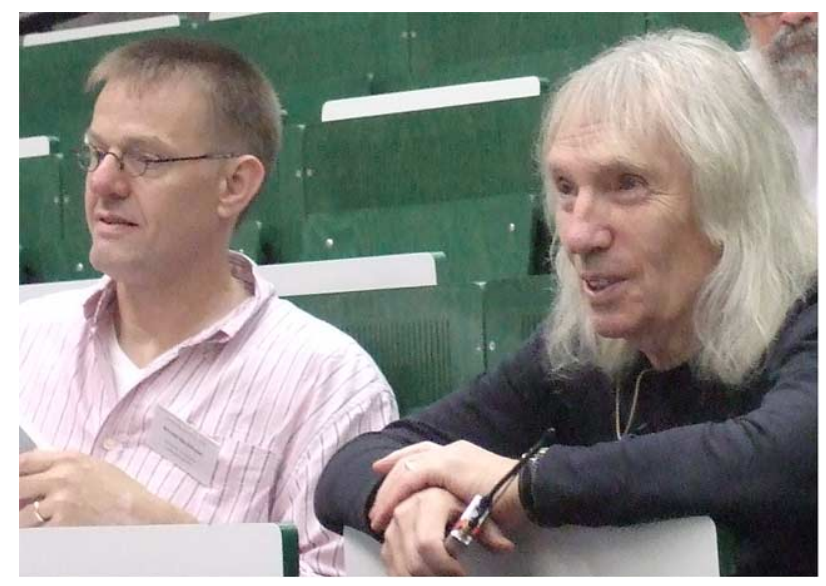

Figure 2. Arnold Beckmann and S. Barry Cooper at the opening of CiE 2009 in Heidelberg. Photo taken by Peter van Emde Boas, July 2009.

quote (often wrongly attributed to Lance Fortnow), "a journal that meets in a hotel"; papers are submitted to a conference and fully refereed before the conference; the accepted papers are presented at the conference and published in a proceedings volume that is printed before and distributed at the conference ("pre-proceedings"). In Computer Science, the quality of the conference is typically measured in terms of how difficult it is to get a paper accepted; a respectable conference should aim at an acceptance rate of $40 \%$ or lower. As a consequence, conferences organized in the style of mathematics with acceptance rates of close to $100 \%$ have trouble being taken seriously by computer scientists.

Since $\mathrm{CiE}$ was a cooperation of at least these two communities (and many more), this gap in publication practice had to be traversed. In order to make the conference attractive for computer scientists, we needed to implement a system that allowed us to be selective for the pre-proceedings while at the same time preserving the inclusive style of mathematics conferences and encouraging everyone in the network to participate. Of course, Barry was one of the most scientifically inclusive people I know and rejecting over half of the submissions went against some of the principles Barry believed in. Already in June 2004, we noticed that the computer scientists and the mathematicians had very different views on that matter and there was an extended e-mail discussion between Barry, Jiři Wiedermann and myself during which the later model of the $\mathrm{CiE}$ conference procedure emerged:

In the refereeing process, we could mark [papers] as 'accepted', 'acceptable' and 'rejected'. The acceptable are told that they will be accepted as 'informal talks'. Then have a second deadline for informal talks [...]. All 'acceptable' talks are automatically accepted as 'informal talks' and all new submissions are checked as for math[ematics] conferences. ${ }^{9}$

Barry was later very proud of our solution to this problem of the two publication practices and was happy to see that other conferences straddling the disciplinary divide adopted similar procedures.

While I had intended to have the discussion of whether there should be a second CiE conference at the first conference in Amsterdam, things developed very differently. In an e-mail updating the members of our community about the upcoming conference, Barry raised this question publicly half a year before CiE 2005 in Amsterdam:

CiE 2006. Do we want to plan a meeting next year? Or is that too soon?

The wide interest in $\mathrm{CiE}$ and its first international conference (extending far beyond the borders of Europe), and the need for forward planning in our coming September proposal for EU funding for the network, makes some of us think we should try and find a host for next year.

\footnotetext{
${ }^{9}$ E-mail from B.L. to S.B.C. and Jiři Wiedermann, 29 June 2004.
} 


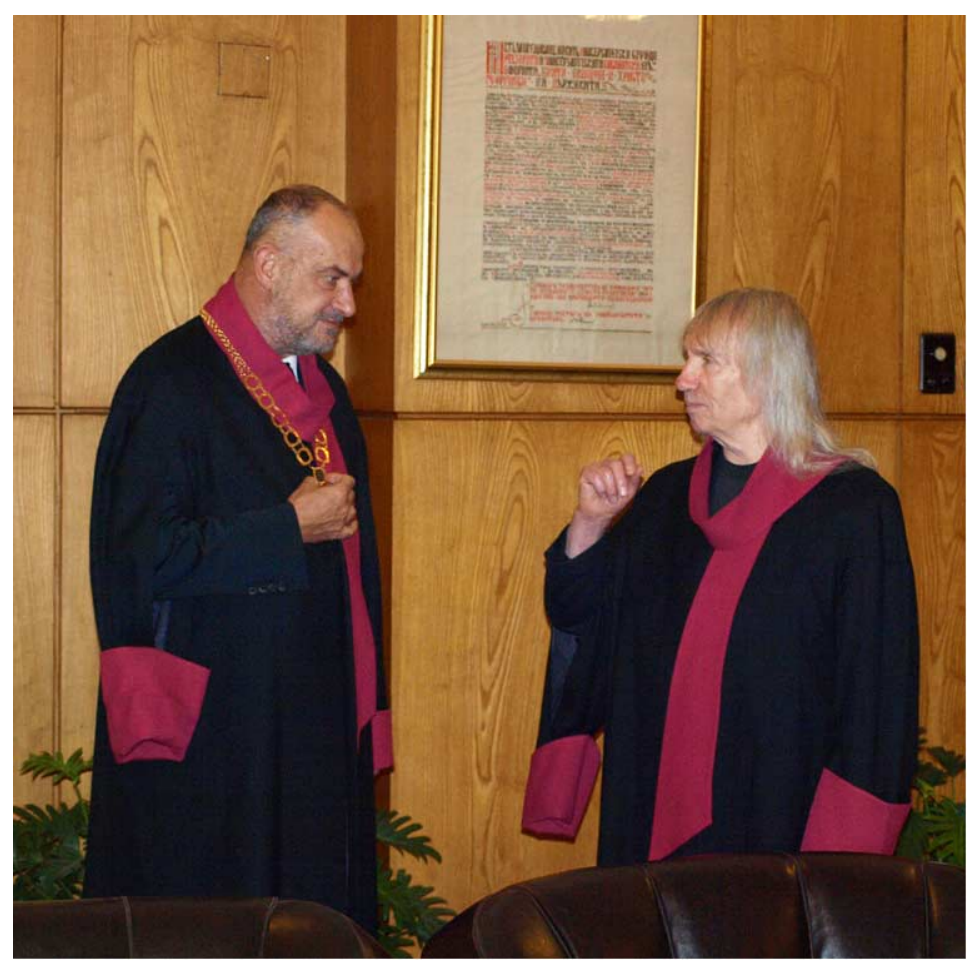

Figure 3. S. Barry Cooper is awarded an honorary doctorate at Sofia University "St. Kliment Ohridski” in Sofia, 2011 (with Ivan Soskov, 1954-2013).

Amsterdam will be a hard act to follow. On the other hand, the experience and goodwill we have built up in just nine months of planning for CiE 2005 makes us optimistic about next year. Please think seriously about bringing CiE 2006 to your own centre, and if interested, let us know. ${ }^{10}$

As in the case of the first conference, things moved very quickly afterwards: within a few days, we had an offer to host CiE 2006 in Swansea and within a few weeks, the decision to develop CiE into a conference series had been effectively taken. From 24 to 26 February 2005, we had a CiE management meeting in Amsterdam during which a small group discussed the upcoming conference and the plans for what would happen after the conference. Barry, Dag Normann, and Andrea Sorbi came to Amsterdam and met with Leen Torenvliet, Peter van Emde Boas, and myself. Many of the decisions for $\mathrm{CiE}$ for the next years were made during this meeting, including the decision about locations, themes, and programme committees of the next four conferences CiE 2006 in Swansea, CiE 2007 in Siena, CiE 2008 in Athens, and CiE 2009 in Heidelberg. The sudden radical shift from "is [2006] too soon?" to having annual conferences in five consecutive years may sound surprising: the explanation is that we had decided to apply for European funding in the Marie Curie programme Series of Events.

A memorable occurrence during the mentioned CiE management meeting in Amsterdam was a dinner at the (very respectable) Indonesian restaurant Aneka Rasa in the red light district of Amsterdam when the Amsterdam mounted police arrived to collect someone who had collapsed in the bathroom. We did not blame the restaurant for this and chose it as the venue for the conference dinner of CiE 2005.

Barry was acutely aware that the success of the Amsterdam conference needed to be followed up by conferences with the same vibe and enthusiasm in order to make sure that the new conference series survived. As one of the co-chairs of CiE 2007 in Siena, he certainly did his part to make sure that this happened. I do not know how Barry did it, but whenever he was personally involved with the organisation of one of the CiE conferences, he attracted

\footnotetext{
${ }^{10}$ E-mail by S.B.C. to the CiE community, 28 January 2005.
} 
attention at a level that the other CiE conferences didn't get: Amsterdam 2005, Siena 2007, and Cambridge 2012, the three conferences in our series with Barry as one of the co-chairs of the programme committee, were by far the biggest of the CiE conferences. At $\mathrm{CiE} 2007$ in Siena we also saw the division of labour between the two co-chairs of the programme committee for the first time: Andrea Sorbi as the local co-chair would be responsible for the local arrangements and Barry as the non-local co-chair would handle communication with speakers and matters of the programme. This division of labour became an important $\mathrm{CiE}$ tradition in later years.

The Alan Turing Year(s). I do not know how long Barry had been thinking about the Alan Turing Centenary, but it was in Siena in 2007 that he raised this issue in a lunch meeting of the CiE steering group, forcefully arguing that 2012 should become the Alan Turing Year and that CiE 2012 should be held in Cambridge. The conference series was in its earliest phase and procedures were slowly being established. As mentioned, the conferences $\mathrm{CiE}$ 2006, $\mathrm{CiE} 2007, \mathrm{CiE} 2008$, $\mathrm{CiE} 2009$, and $\mathrm{CiE} 2010$ had all been arranged very quickly in a top-down procedure in order to write two proposals for European funding for the conference series (submitted in May 2005 and May 2006, respectively; both unsuccessful). After CiE 2007 in Siena, we felt that the series was going well and should develop proper procedures for deciding about future meetings. In fact, $\mathrm{CiE} 2011$ was supposed to be the first test case with a bid announced by Sofia University. Barry's energetic proposal to make a commitment for CiE 2012 in Cambridge without following any procedure went against the desire to develop a principled decision process, and resulted in unavoidable clashes between Barry and me as the chair of the Steering Committee. I felt that it was premature to make decisions about CiE 2012 before we even had a bid from Sofia (we would not get that bid before March 2009), and Barry was upset that his vision of celebrating Turing's birthday on 23 June 2012 in Cambridge, the place at which that Turing had felt so much at home, was being slowed down by administrative hassles. As always, we found a way to implement Barry's powerful vision.

In April 2008, Barry formed the Turing Centenary Advisory Committee (TCAC). According to the website of the Alan Turing Year, the fully formed TCAC had 96 members, including representatives of publishers, learnèd and professional societies, activist groups, funding agencies, museums, companies, and had Sir Dermot Turing as Honorary President. In comparison, the beginnings of the TCAC in 2008 were surprisingly small-scale and academic; its members, apart from Barry and myself were Samson Abramsky, Arnold Beckmann, Luca Cardelli, Anuj Dawar, Andrew Hodges, Martin Hyland, Mogens Nielsen, Jeff Paris, Andrew Pitts, Christof Teuscher, and John Tucker. The list shows a Cambridge focus that reflects that CiE 2012 and the 23rd of June were considered the pivotal points of the early plans for the Alan Turing Year.

Taking this Cambridge focus into account, it is not surprising that another part of the early plans for the Alan Turing Year was the organisation of a semester research programme at the Isaac Newton Institute in Cambridge. There had been earlier attempts to propose a computability-related programme at the Newton Institute: I got involved during a lunch meeting at CiE 2006 and became one of the applicants (with John Tucker and Barry) of an unsuccessful proposal focusing on physical computation (submitted in the summer of 2006). At CiE 2008 in Athens, the idea of incorporating a Newton Institute programme in the Turing celebrations in Cambridge was raised and discussed between Arnold Beckmann, Barry, John Tucker, and myself. In the following months, we accidentally managed to work in parallel on this proposal: for some reason, I was under the impression that Barry had delegated this task to Arnold and myself.

When Barry found out that two different groups of people had been simultaneously working on the proposal, he became extremely angry. It may come as a surprise to many people that Barry could get angry. Barry's anger was not easy to spot: it did not manifest itself in rage and noise. In fact, when Barry was angry, he hardly raised his voice. You could notice that Barry was angry from his choice of words and phrases, from the disappearance of his otherwise omnipresent smile, and in general by a more serious facial expression. In e-mails, a means of communication that Barry loved and used a lot, these indicators of anger were even harder, if not impossible, to spot; this sometimes resulted in escalation. The fact that two teams had been working on a Turing-related Newton Institute proposal was one of those cases: when Barry informed me in an e-mail "I'm absolutely blazing", ${ }^{11}$ I was completely taken by surprise. Luckily, e-mail escalations like this could be resolved by switching from e-mail to more personal means of

\footnotetext{
${ }^{11}$ E-mail from S.B.C. to B.L., 25 November 2008.
} 


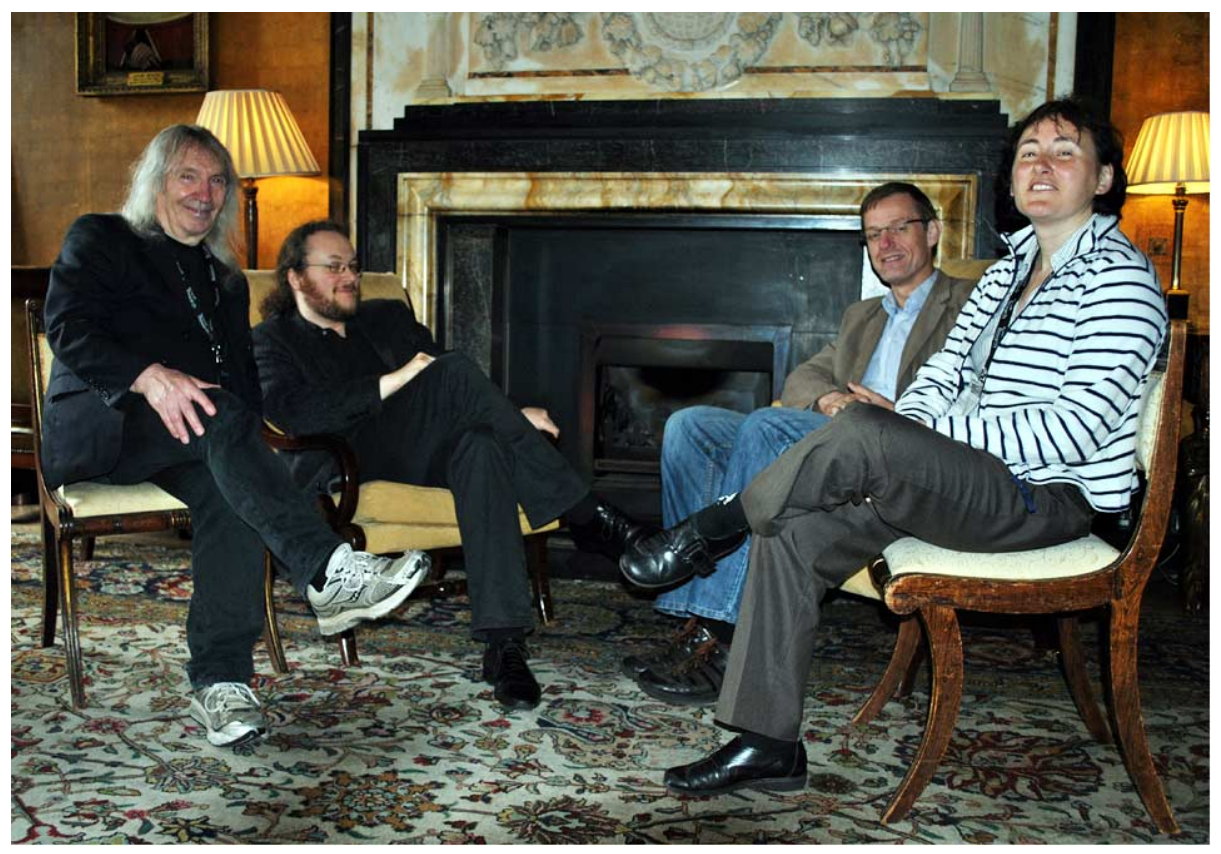

Figure 4. Four of the five organisers of the programme "Semantics \& Syntax": S. Barry Cooper, Benedikt Löwe, Arnold Beckmann, Elvira Mayordomo (from left to right). Photo taken by Sara Wilkinson in the Old Combination Room at Corpus Christi College, Cambridge, June 2012.

communication such as the phone; also in the case of the Newton Institute proposal crisis, a phone conversation in the evening calmed the waves.

The research programme "Semantics \& Syntax" was accepted by the Isaac Newton Institute for the first half of the Turing centenary year 2012; Arnold Beckmann, Barry, Elvira Mayordomo, Nigel Smart, and I were the organisers of this programme. I am currently (November 2015) writing this text while sitting in office F1 at the Isaac Newton Institute; this is the same office that I had during "Semantics \& Syntax" in 2012. This fact shows that Barry's initiative had a profound effect on me and my career, creating links with the Isaac Newton Institute, Corpus Christi College, and the University of Cambridge in general, and I am very grateful for Barry's role in these developments. "Semantics \& Syntax" brought some of the key players of the Alan Turing Year to Cambridge for the first half of the centenary, creating the headquarters of the Alan Turing Year at the Isaac Newton Institute. Part of the centenary was also the launch of the journal Computability during CiE 2012: the publisher IOS Press invited the members of the editorial board for drinks in the Bursar's Garden of Corpus Christi College in Cambridge, hosted by Richard McMahon, the college's president (until 2015).

The Alan Turing Year became much bigger than we had all imagined when we started with the preparations in 2007 and 2008: with Turing-related conferences and events on all continents and a sheer unbelievable number of activities, Barry travelled the globe. At the Isaac Newton Institute, Barry's office was F2 next to mine; his iPhone was set to silent vibration mode, but every incoming e-mail, every incoming text message, and every new tweet caused the phone to vibrate on Barry's desk, producing a sound that could be heard through the wall. And Barry's phone was constantly vibrating.

After 2012, Barry was not willing to declare the Alan Turing Year closed: Turing-related activities continued in 2013 and Barry tacitly changed its name to "Alan Turing Years" in June 2013. And once more, his decision was right, as Alan Turing became more and more present: the book Alan Turing - His Life and Impact, edited by Barry and Jan van Leeuwen won the 2013 Award for Excellence in Physical Sciences \& Mathematics and the R.R. Hawkins Award from the Association of American Publishers; the Queen granted a Royal Pardon to Alan Turing on Christmas Eve 2013; Benedict Cumberbatch starred as Alan Turing in the 2014 Academy Award winning motion picture The Imitation Game; and Turing's notebook was discovered and auctioned for over a million U.S. dollars at 


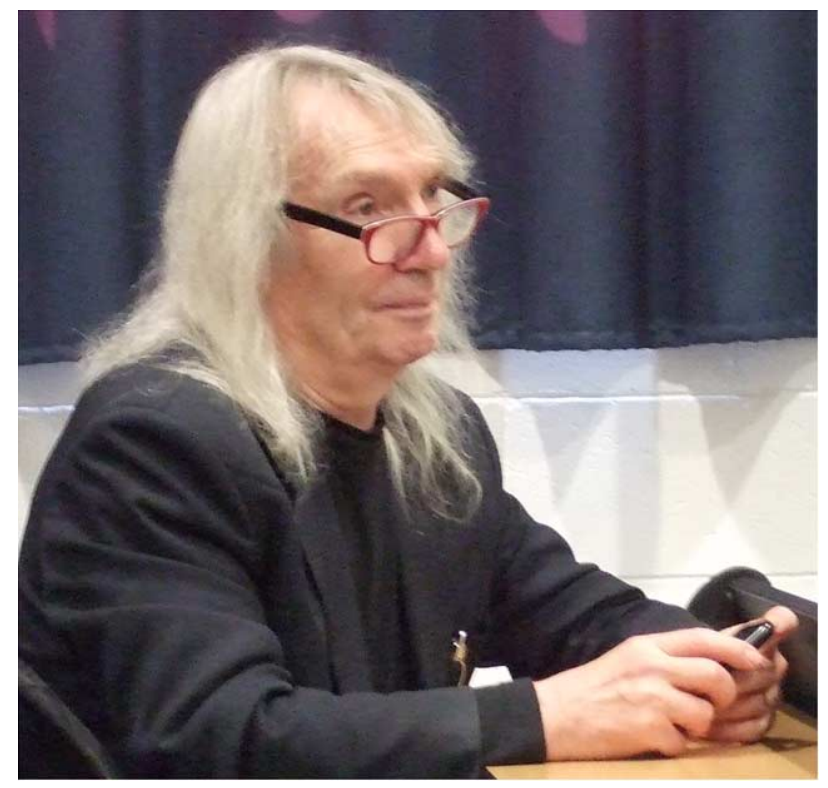

Figure 5. S. Barry Cooper at CiE 2013 in Milan. Photo taken by Peter van Emde Boas, July 2013.

Bonham's in New York in April 2015. Barry became visible as Turing's spokesperson, being interviewed by national newspapers, for BBC Today, and for Sky TV News. If you watch the short Sky TV News interview with Barry about Turing, ${ }^{12}$ you will find it very difficult to believe that he is not among us anymore.

A transition for the Association CiE. Barry realised that the fact that the CiE community had a small and very close-knit core had been an advantage in its earlier years, but increasingly developed into a liability: the key figures of the CiE community became committed to other projects, not least Barry himself with the Alan Turing Years. Barry was particularly worried about his own succession as president of the Association.

In order to get more people actively involved with the Association, Barry proposed a number of motions to overhaul the constitution of the Association at the Annual General Meeting of the Association CiE in Budapest 2014. Once more, Barry and I disagreed about some of the details, in particular the wording of the motions. Being too busy with other things, we did not have the chance to properly discuss and coordinate our positions before the General Meeting and our disagreement became publicly apparent in the debate during the General Meeting. After some debate, the members voted against Barry's motions. The minutes of that General Meeting report:

Several members of the assembly expressed the view that the problem is not concerning the spirit of the motions, on which there is general agreement, but their wording in the current form. The following motion was then proposed to the assembly: 'That the board should submit, after a process of consultation, constitutional amendments implementing the above proposals [...] to a vote of the Membership' ${ }^{13}$

This new motion was unanimously adopted; during a board meeting of the Association in January 2015 in London, the Board of the Association arranged a procedure in which constitutional amendments would be negotiated; in April and May 2015, the Board polished the amendments in a three-week long intensive e-mail discussion expertly moderated by Barry; during the Annual General Meeting in Bucharest on 2 July 2015, the members of the Association unanimously voted in favour of the amendments; this vote was confirmed by an online vote by all members of the Association (with $96.6 \%$ of all votes cast in favour); and so, finally, the new constitution will be implemented by

\footnotetext{
${ }^{12}$ Mathematician Barry Cooper. Turing Pardon. Computer Pioneer and Codebreaker Alan Turing given Royal Pardon. Sky TV News, 24 December 2013.

${ }^{13}$ Minutes of the AGM of Association Computability in Europe, Budapest (Hungary), 26 June 2014, taken by Olivier Bournez.
} 


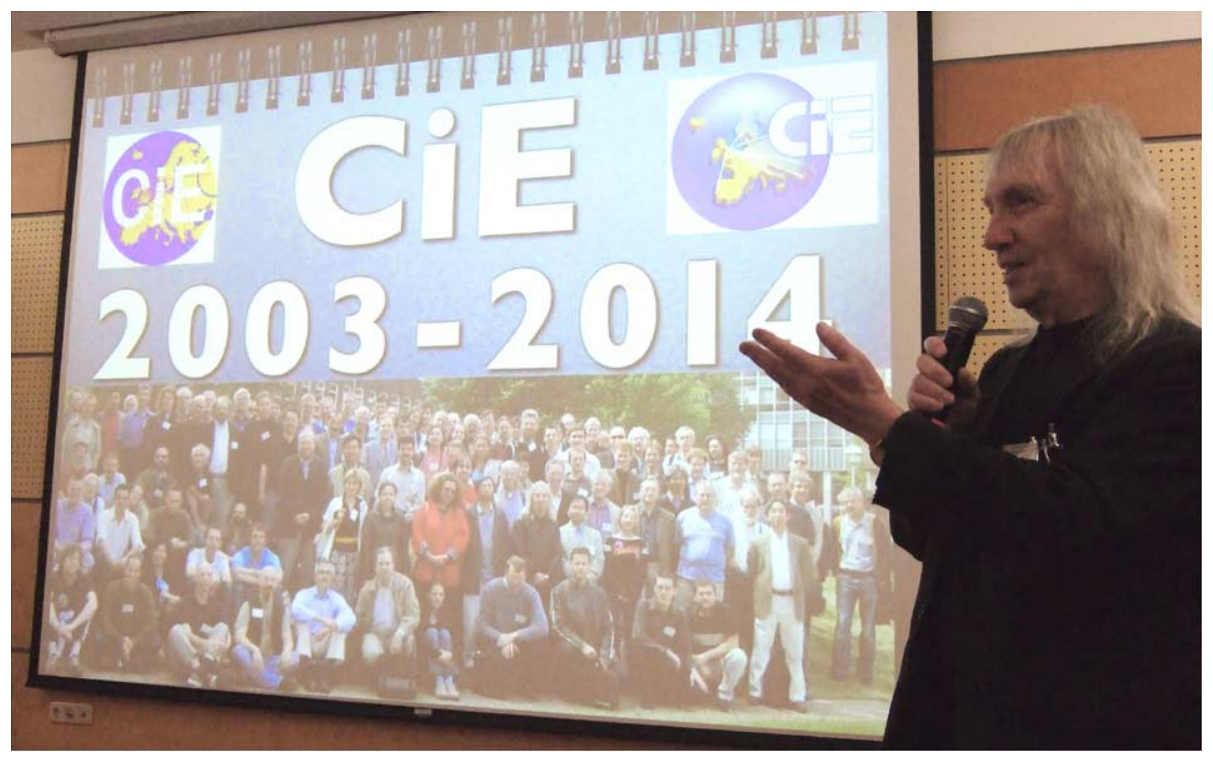

Figure 6. S. Barry Cooper at the opening of CiE 2014 in Budapest. Photo taken by Peter van Emde Boas, June 2014.

the time of CiE 2016. Once more, we have seen the familiar pattern of clash and reconciliation between vision and procedure.

Barry retired as President of the Association in 2015 and Dag Normann took over as Acting President for one year. The old constitution did not foresee any role for the past president of the Association, whereas according to the proposed new constitution "any member who was the President of the Association will remain on the Council ex officio for the eight years following her or his term of office as President". ${ }^{14}$ As a consequence, Barry's retirement from the presidency in 2015 implied that he was not part of the Association CiE governance structure until the new constitution is implemented in the summer of 2016; Barry referred to this gap as a "sabbatical from CiE" and was looking forward to resuming his role in the Association as Past President after CiE 2016. Unfortunately, we shall not get the opportunity of welcoming Barry to the newly formed Council next year and we shall not be able to benefit from his visions anymore.

${ }^{14} \mathrm{New}$ constitution of Computability in Europe; unanimously accepted by the AGM of the Association CiE, 2 July 2015, Bucharest, Romania. 